\title{
Design and Fabrication of Centre Line Marker
}

\author{
Jeremiah. R, Prabhakaran. D, Jothi Prakash. V. M, Prasath. P, Raghavendran. J
}

\begin{abstract}
We have pleasure in introducing our new project "DESIGN AND FABRICATION OF CENTER LINE MARKER", it is a genuine project which is fully equipped and designed to find out the center point or mark a center line in beam or rod in an industry of mass production. This forms an integral equipment of best quality. This product underwent vigorous tests and it's precise. Center line marker uses the "PROPERTY OF ISOSCELES TRIANGLE".

The "CENTER LINE MARKER" can be used to mark center points and lines using pencils and also dot punch can be used to points for drilling and other purposes. This is very use full in mass production and saves much time. The precision and accuracy of the device will help to manufacture quality products with shorter lead time.
\end{abstract}

Keywords - isosceles triangle, lead screw, arms, proximity sensors, electronic circuit.

\section{INTRODUCTION}

The Center line of a beam is usually marked in order to drill holes into it. With the help of these holes two beams can be joined together. For machining a keyway on the center axis of the beam, the center line marker can be used effectively.

The principle of center line marker revolves around the property of isosceles triangle. A triangle can be termed as isosceles when the two sides of the triangle are equal. And also, a complementary property to the above said property is that, the line drawn from common vertex of the equal sides of the isosceles triangle to the third side, bisects the third side into two equal halves. In other words, the common vertex is at the center of the third side.

In Center line marker, the length of the third side of the isosceles triangle is analogous to the width of the beam, whose center line is to be marked. The equal sides of the isosceles triangle are replaced by two equal arms made up of stainless steel or Aluminum. A scriber is attached to the common joint of equal arms which represents the common vertex of the isosceles triangle. A scriber is used to mark the midpoint of the beam while the pencil can be used to mark the center line.

\section{CONSTRUCTION}

\section{A. Submission of the paper}

The centerline marker consists of a base plate which houses all other components over it. The front plate and the movable middle plate act as jaws for holding the beam. A third plate called the last plate is also fixed to the base plate.

Revised Manuscript Received on 14 August, 2019.

Jeremiah.R, Mechanical Engineering, Easwari Engineering College, chennai, Tamilnadu, India. (Email: jeremiahpeter1977@gmail.com)

Prabhakaran.D, Mechanical Engineering, Easwari Engineering College, chennai, Tamilnadu, India. (Email: prabha.caps@gmail.com)

JothiPrakash.V.M， Mechanical Engineering, Easwari Engineering College, chennai,Tamilnadu, India.(Email: jothiprakashsvce@gmail.com)

V. M, Prasath. P,

Raghavendran. J
The front plate and last plate have three drilled holes to house roller bearings. The translation of the movable middle plate along the length base plate is achieved by the assistance of a lead screw.

The lead screw connected to the front plate and the last plate through roller bearings. Thus, the free rotation of the lead screw is possible by the help of roller bearings. The middle plate has a drilled hole over which a brass nut is fixed with the help of bolts. The lead screw passes through this brass nut.

The nut is capable of moving over the lead screw, and thus the entire middle plate. The equal arms are fixed to the Front plate and the middle plate. The other free end of the equal arms has free holes that can hold the scriber or the pencil. Two rollers are attached to the roller bearings in the front and last plate.

An ultrasonic proximity sensor is placed over the base plate. A probe is placed over the middle plate in the path of ultrasonic sensor. The proximity sensing element is combined to the Arduino and LCD.

\section{CLAMPING MECHANISM}

A clamp is a device that is used to hold the work piece while any operation is performed on it. There are variety of clamps used for various operations. Few are temporary, used to hold parts while necessary operations are performed on them while others are permanent.

\subsection{Hand Screw Clamp}

It is also called Tool maker's clamp. Wooden Hand Screw Clamps are used for making repairs in furniture. This type of hand screw clamp is used in centerline marker and it has a lead screw and threaded nut for the movement of the clamp and it has aluminium plates as the clamping elements.

\subsection{Calculation For Clamping Action}

The force exerted by the fixed front plate and the movable middle plate can be determined by the 'resistance to deflection' of the object between the jaws.

For example, consider placing a brick between the jaws, it will be very hard to move the handle to obtain even a small deflection. But, if the brick is replaced with a sponge deflection is easily achieved.

Objects placed between the clamps react back with a resistive force that depends upon a property called stiffness and also the amount of force applied.

If we consider a fixed amount of deflection, say $1 \mathrm{~mm}$, then to compress a brick $1 \mathrm{~mm}$ requires considerably more force than for a sponge. The force equals the stiffness times the deflection. 
For an Aluminium block placed between the clamps,

Dimensions of the block $=0.2 \times 0.075 \times 0.012$

Volume $=0.00018 \mathrm{~m}^{3}$

Density of Aluminium $=2700 \mathrm{~kg} / \mathrm{m}^{3}$

Mass of the block

$$
\begin{aligned}
& =\text { Density X Volume } \\
& =2700 \times 0.00018 \\
& =0.486 \mathrm{~kg}
\end{aligned}
$$

Weight of the block $=0.486 \times 9.81=47.67 \mathrm{~N}$

Specific modulus or Specific Stiffness of Aluminium $=27$

Specific modulus $=($ Stiffness $/$ Weight $)$

$$
\begin{aligned}
\text { Stiffness } & =\text { Specific modulus X Weight } \\
& =27 \text { X } 47.67 \\
\text { Stiffness }= & 1287.07 \mathrm{~N} / \mathrm{m} \\
= & (1287.07 / 1000) \mathrm{N} / \mathrm{mm} \\
= & 1.287 \mathrm{~N} / \mathrm{mm}
\end{aligned}
$$

For Deflection $=1 \mathrm{~mm}$

$$
\begin{aligned}
& \text { Stiffness } \quad=\text { Clamping force } / \text { Deflection } \\
& \text { Clamping force }=\text { Stiffness X Deflection } \\
& =1.287 \text { X } 1=1.287 \mathrm{~N}
\end{aligned}
$$

Thus $1.287 \mathrm{~N}$ of clamping force is required to produce a clamping action between the jaws.

\subsection{Linear Motion}

Linear motion is also termed as rectilinear motion. It is a 1-D motion following a linear path and can be described using only one coordinate.

There are two types of straight line motion:

Uniform: Where the velocity is constant.

Non-uniform: Where velocity varies with time.

According to Newton's first law of motion, objects tend to be in motion with constant velocity or rest unless and until they experience an external force. But generally, external elements such as gravity and friction can make body change its motion's direction, thus motion cannot always be linear.

For centerline marker the linear movement is achieved by using a lead screw and brass nut moving over it.

\subsection{Lead Screw}

A lead screw (or lead screw) is used to convert the turning motion into linear motion. They are horizontally rotating screws used for moving the carriage linearly.

\subsection{Calculation For Lead Screw}

Lead can be defined as the the distance moved per screw revolution.

Lead $=$ Pitch, for single start screws

Lead $=$ N X Pitch, for multi-start

Pitch is the distance between two successive threads in a screw.

$$
\begin{aligned}
& \text { Lead = Pitch } X \mathrm{~N} \\
& \text { ' } \mathrm{N} \text { ' is the number starts, } \mathrm{N}=4 \\
& \text { No. of threads per mm }=0.5 \\
& \begin{aligned}
\text { Pitch }=1 /(\text { No. of threads per } \mathrm{mm}) \\
\quad=1 / 0.5=2
\end{aligned} \\
& \text { Lead }=2 \mathrm{X} 4=8 \mathrm{~mm} .
\end{aligned}
$$

\section{DESIGN PROCESS}

Design phase is carried out by the help of computer software like CATIA. The process begins with identification of need and then making the decision. After much iteration, the required design is obtained.

Software used: CATIA V5, ANSYS 15.0

\subsection{Catia}

CATIA V5 is acronym for Computer aided threedimensional interactive application, Version 5.This Software was used for designing the components and the assembly. Dassault systems created CATIA.

CATIA enables the user to create components in various working environments namely, Part modeling, Sheet metal, Surface modeling and Assembler. It is equipped with tools for complete definition of the part. CATIA finds its application in design of tools. In, Aerospace engineering an additional environment called aerospace sheet metal design provides the designer to join the qualities of generative sheet metal design and generative surface design.

As per the above mathematical calculation, the design parameter of Centre line markers calculated and designed. As per the calculated design parameters, the centre line marker is modeledusing modeling software, CATIA. The below mentioned figure shows the 3Dassembly of the Centre line marker.

\section{SELECTION OF MATERIAL}

After a series of analysis, the material selected for the equipment is aluminium, because of the following reasons

1. It is light in weight as the equipment must be easily portable

2. It has good strength to withstand load and

3. It can be machined easily to required shape.

Structural components such as Front, Middle, Last and the Base plate are made up of aluminium 6031.

The equal arms are also made up aluminium strips.

The coupler is also made up of aluminium.

The scriber is made up of HS steel with a pointed tip.

The rollers are made up of MS round rod.

The Lead screw is made up of stainless steel.

The nut is made up of Brass

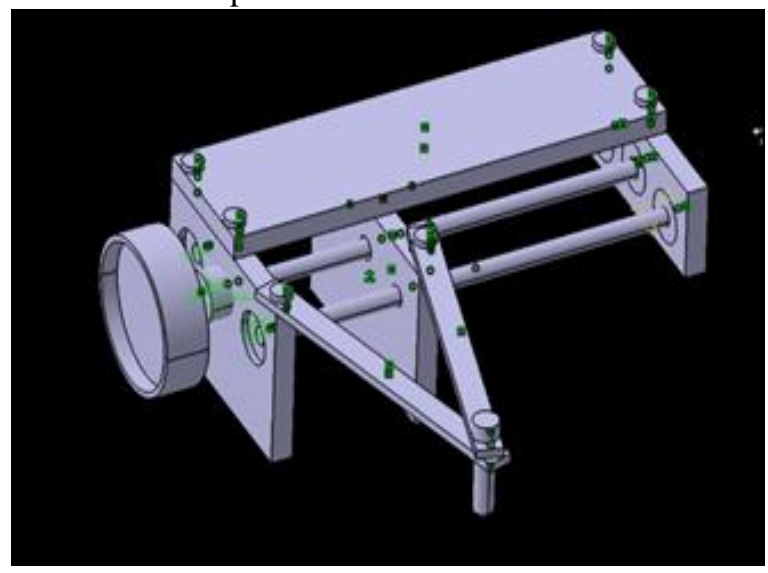




\subsection{Aluminium}

Aluminium is abundantly available element on earth and it is the $3^{\text {rd }}$ most common element. It constitutes $8 \%$ of the earth's crust. Aluminium is more versatile and is used next to steel widely.

Aluminium is obtained from its ore, bauxite. Bauxite is changed into alumina through Bayer Process. Aluminium is later obtained from alumina by Hall-Heroult process.

\subsection{Application OfAluminium}

\section{Properties of Pure Aluminium:}

Ductility, conducts electricity and prevents corrosion.

Thus, aluminium is used for making foil and cables. Suitable alloying is provided for higher strengths needed for other applications. It's ratio of strength to weight is greater than that of steel.

By combining the desirable properties aluminium, it is used in variety of operations. These products range from heavy structural members to very thin foils.

\subsection{Alloys Designation}

Aluminium is usually alloyed with zinc, magnesium, silicon,copper and lithium.

There are over 300 wrought alloys and only 50 are commonly used. They are identified in 4 figure standards originated in USA.

The non-heat treatable alloys' properties may change by cold working operation. Example: Cold rolling.

The degree of adjustment is proportional to the degree of cold working process. Annealing or stabilizing thermal treatment after the cold working process can also change the properties.

Nomenclature by letters $\mathrm{O}, \mathrm{F}$ or $\mathrm{H}$ followed by one or more numbers are used to describe these processes, As in Table 6, first number defines the work condition and the second number the rate of tempering.

\subsection{Physical Properties OfAluminium}

\begin{tabular}{|c|c|}
\hline Property & Value \\
\hline Atomic number & 13 \\
\hline Atomic Weight (g/mole) & 26.98 \\
\hline Valency & 3 \\
\hline CrystalStructure & FCC \\
\hline Melting Point $\left({ }^{\circ} \mathrm{C}\right)$ & 660.2 \\
\hline Boiling Point $\left({ }^{\circ} \mathrm{C}\right)$ & 2480 \\
\hline MeanSpecific Heat $\left(\mathrm{cal} / \mathrm{g} .{ }^{\circ} \mathrm{C}\right)$ & 0.219 \\
\hline $\begin{array}{l}\text { Thermal Conductivity }(\mathrm{cal} / \mathrm{cms} \text {. } \\
\left.{ }^{\circ} \mathrm{C}\right)\end{array}$ & 0.57 \\
\hline Co-Efficient of Linear $\left(\mathrm{x} 10^{\left.-6 /{ }^{\circ} \mathrm{C}\right)}\right.$ & 23.5 \\
\hline $\begin{array}{c}\text { Electrical Resistivity at } 20^{\circ} \mathrm{C} \\
(\Omega . \mathrm{cm})\end{array}$ & 2.69 \\
\hline Density $\left(\mathrm{g} / \mathrm{cm}^{3}\right)$ & 2.6898 \\
\hline Modulus of Elasticity (GPa) & 68.3 \\
\hline Poisson's Ratio & 0.34 \\
\hline
\end{tabular}

\section{ANALYSIS\& RESULTS}

\section{Ansys R15.0}

Ansys, Incis associated with developing simulation software. It is used to create product geometry in the same workbench and create simulations for the same as well. This software is used to test a product's strength, temperature characteristics, fluid motion and electromagnetic characteristics.

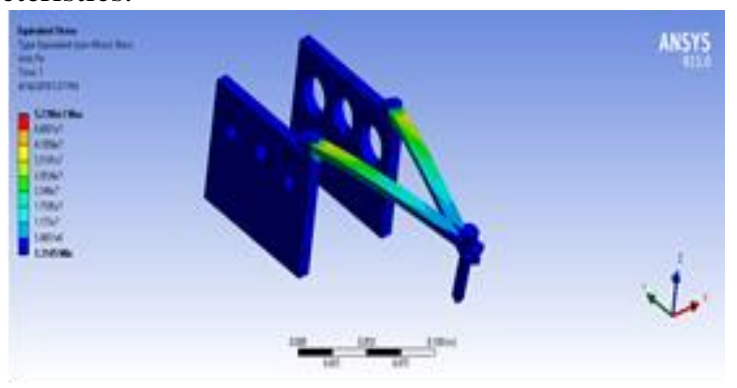

Load of $300 \mathrm{kgf}$ or $2943 \mathrm{~N}$ at the head of the scriber. The bottom surface of the jaws is fixed.

The maximum equivalent stress of the system was observed to be $5.27 \times 10^{7} \mathrm{~Pa}$

Yield strength of aluminium $=240 \mathrm{MPa}$

Factor of safety $=($ Yield strength/ Working stress $)$

$\mathrm{FOS}=\left(240 \times 10^{6}\right) /\left(5.27 \times 10^{7}\right)$

$\mathrm{FOS}=4.55$

Hence, the Design is Safe

\section{ELECTRONIC CIRCUIT}

The electronic circuit used in this project is distance measurement using an ultrasonic sensor connected to an arduino board. This is used to measure the length of the work piece of which the center is to be marked.

\subsection{Electrical Components}

The electrical components used in this project are as the following and connection.

1. ARDUINO UNO

2. BREAD BOARD

3. ULTRASONIC SENSOR

4. LCD DISPLAY

5. CONNECTING WIRES

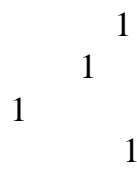

\subsection{Arduino Uno}

Arduino is an organization associated with both software and open source hardware. Microcontroller kits and Singleboard microcontrollers are designed and produced by this community for building interactive object sand digital components that can control and sense objects.

Arduino has the GNU or General Public License, thereby allowing the creation of software distribution and arduino boards by anyone.

A wide range of microprocessors and controllers are used in design of arduino boards. Sets of analog and digital input/output pins are provided to these boards. These can be interfaced to several other breadboards or expansion boards. Serial communications interfaces are provided to the board.

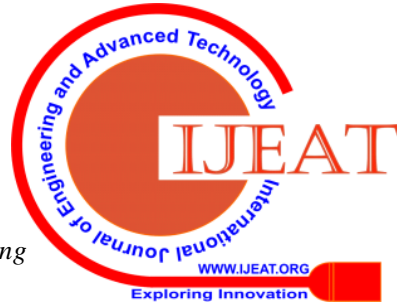


These may include Universal Serial Bus which may be for send the data and programs personal computers. Programming languages $\mathrm{C}$ and $\mathrm{C}++$ are used to program the microcontrollers. The Project arduino gives integrated development environment (IDE) which works with basis of the Project, Processing language.

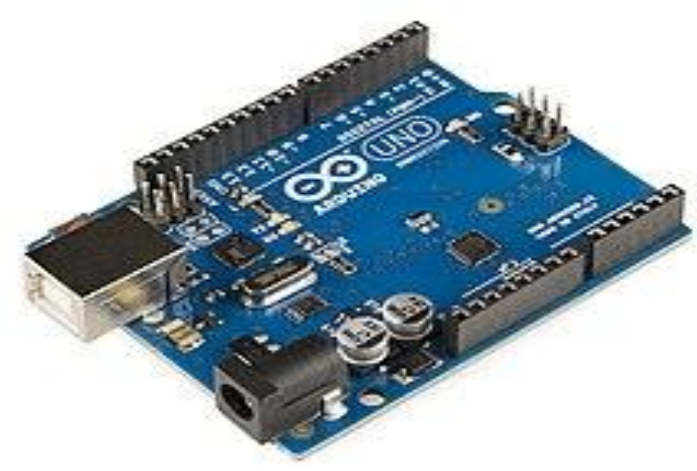

\subsection{Ultrasonic Sensor}

The distance to an object can be measured using a device called the Ultrasonic sensor. The distance is measured by giving out a wave of sound from the sensor at a definite frequency and receiving that sound wave after it bounces back. The time taken between the generation of sound wave and the sound wave bouncing back is recorded. With the recorded time, it is possible to determine the distance between the object and the sensor.
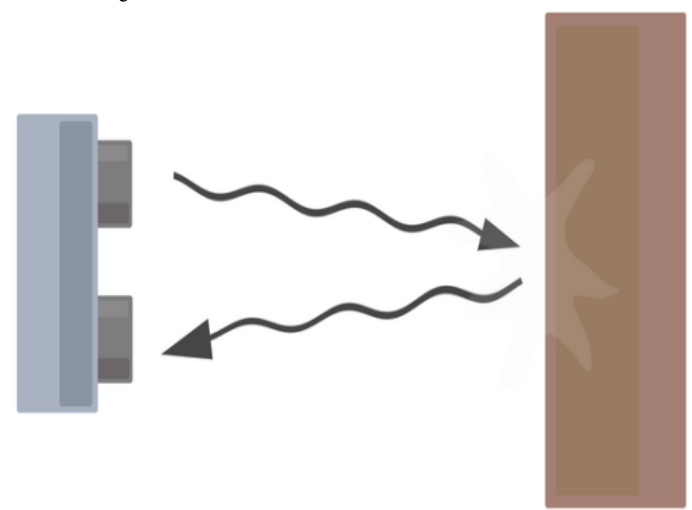

The velocity is $1129 \mathrm{ft} / \mathrm{s}$ for sound in air. The time taken for the sound to return back to the sensor is multiplied with the velocity of sound in air $(1129 \mathrm{ft} / \mathrm{s})$ to find the total distance of the sound wave. The distance from the sonar to the object and distance from the object to the sensor is the total distance travelled. Hence the actual distance is found by simply dividing the total calculated distance by 2 .

Ultrasonic sensors will not be detecting some objects. This is because of position or shape of the object which causes the sound wave deflects away without reaching the Ultrasonic sensor. Certain objects maybe smaller to reflect only very small amount of sound, that cannot be detected by the sensor. The accuracy of detection is also affected by foreign particles and objects in the path of the sound wave.

These objects might absorb the sound before it reaches the sensor. Thus, all these factors are to be considered while measuring the distance using the ultrasonic sensor.

\subsection{LCD Display}

A LCD is an optical output device that is electronically modulated. It is abbreviated as Liquid crystal display. It works based on the light modulating the properties of crystals in the liquid. The light is not emitted by the crystals directly. To produce output in the display in monochrome or color, back lights or reflectors are used. LCDs can be used as a common computer display or stationary image screens with less content of information, which can be either displayed or hidden. Both kinds share the same features, except the computer display is made up of large number of small pixels while the stationary image type has larger constituents.

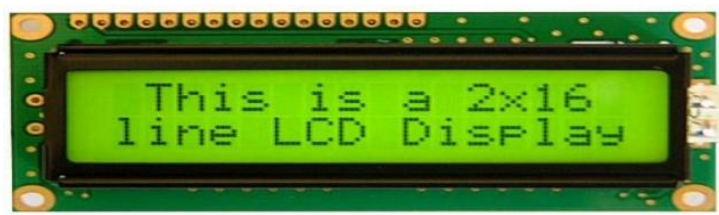

In variety of applications namely, computer monitors, aircraft cockpit displays, instrument panels, LCD televisions and signage, LCDs are used.

\subsection{Breadboard}

A breadboard is a versatile device used for testing and designing circuits without soldering. The electronic components in the circuits are connected with each other by embedding their terminals into the holes of the breadboard. A strip of metal is present under the board; this metal strip connects the holes on the board.

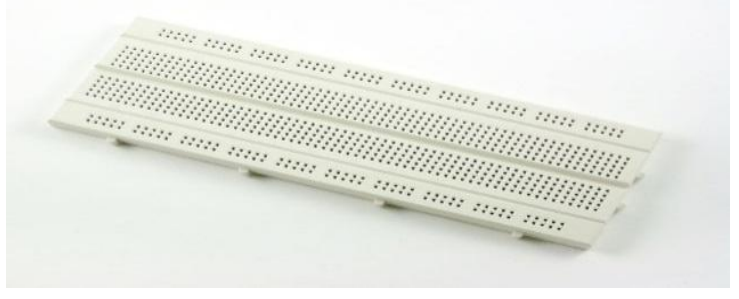

CIRCUIT DIAGRAM.

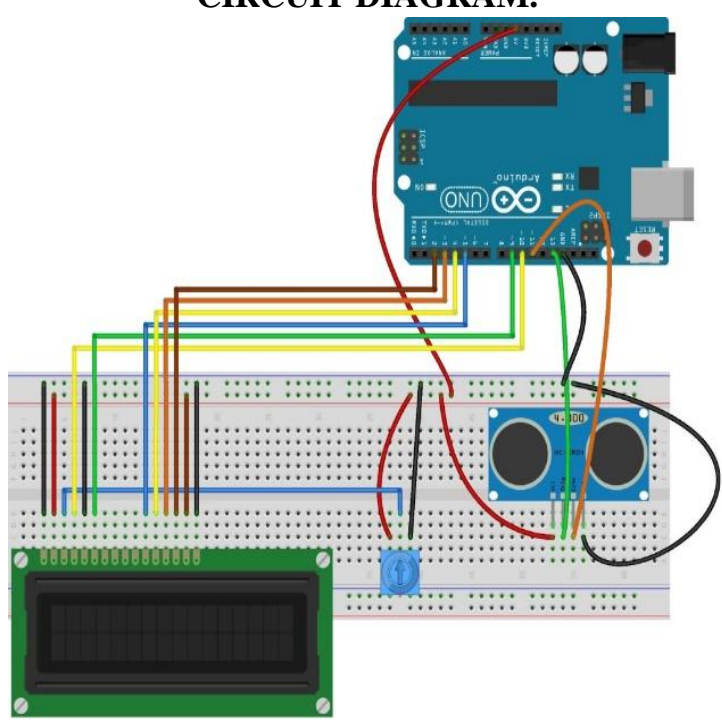

Published By:

Blue Eyes Intelligence Engineering

\& Sciences Publication 


\section{WORKING}

The ultimate goal of using Centre line marker is to find the midpoint or the center line of beams or rods. The principle of center line marker revolves around the property of isosceles triangle. A triangle can be termed as isosceles when the two sides of the triangle are equal. And also, a complementary property to the above said property is that, the line drawn from common vertex of the legs of the isosceles triangle to the base, bisects the base into two equal halves. In other words, the common vertex is at the center of the third side.

This property of isosceles triangle is effectively used in the center line marker. The center line marker consists of components that are analogous to the sides of an isosceles triangle

The equal arms in the center line marker represent the equal legs of isosceles triangle, while the distance between the clamps is analogous to the base of the triangle.

The clamps can be adjusted according to the width of the work piece by the help of lead screw. Thus, it can be said that, when the work piece is held tight between the clamps, the width of the work piece represents the base of the isosceles triangle.

Since the equal arms are bolted to the fixed and movable jaw, the spontaneously align themselves in such a way that, the common vertex bisects the base (width of the work piece) of the triangle, thereby satisfying the property of isosceles triangle.

A scriber or pencil can be fixed at the common vertex to mark the midpoint.

The center line marker is provided with two rollers placed over the work piece. These rollers permit the movement of the center line marker along the length of the work piece, thus marking the center line.

The rotation of lead screw is achieved by using a wheel with shaft coupled with the lead screw by using a coupler. The clamps can be adjusted accordingly by rotating the lead screw with the help of wheel.

The proximity sensor is made to detect the movement of a probe coupled to the movable middle plate. The proximity sensor is placed on the fixed front plate. Thus, when the clamping is attained, the distance measured by the proximity sensor is equal to the width of the beam. The arduino board is made to work with the ultrasonic proximity sensor. The width of the beam is displayed in the LCD which receives the information from the arduino board.

\section{ADVANTAGES}

1. Very simple and easy operation.

2. Very less time consumption.

3. Manual error is eliminated.

4. Easily portable.

5. Manufacturing the equipment is less complex.

\section{CONCLUSION}

The Center line marker can be used as a tool that be effectively used to find the midpoint of the beams and to mark the center lines accurately. In addition to that with the help of electric circuit and ultrasonic proximity sensor, the width of unknown beam can also be found momentarily.

The key advantage of using this equipment is that it eliminates manual error. As the manual error is reduced the quality of the product is increased.

Thus, this equipment can readily be used in Workshops, Industries and Colleges. Secondly, this equipment is affordable for everyone.

\section{FUTURE SCOPE}

Moreover, this equipment can be produced in various grades in future, so that it can mark beams of different width and material

\section{REFERENCES}

1. https://www.manufacturingterms.com

2. https://www.engineeringtoolbox.com

3. https://www.researchgate.net

4. http://www.thestructuralengineer.info

5. https://us.misumi-ec.com

6. Massimo Banzi, Michael Shiloh, "Getting Started with Arduino: The Open Source Electronics Prototyping Platform".

7. Ron Fournier, Sue Fournier, "Metal Fabricator's Handbook"

8. Sir Neville Francis Mott, H. Jones, "The Theory of the Properties of Metals and Alloys"

9. Z. Marciniak, J. L. Duncan, S. J. Hu, "Mechanics of Sheet Metal Forming"

\section{AUTHORS PROFILE}

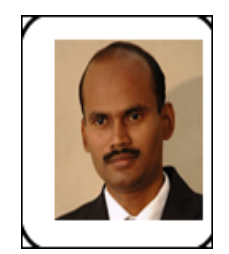

Jeremiah.R, B.E.Mechanical Engineering, M.E.Industrial Engineering, published 4 journals,attended several conferences, member in Indian society of Mechanical Engineersand Indian Science Congress Association.

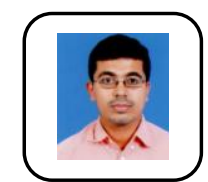

Prabhakaran.D, B.E-Mechanical Engineering, M.E-Internal combustion Engineering, Published one national level paper in 2018 and attended one national conference in 2015 .

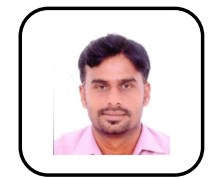

JothiPrakash V. M, B.E-Mechanical Engineering, M.E- CAD, Published four international level papers and Attended four international level conference.

\section{APPLICATION}

1. Sheet metal working process.

2. Wood working process.

3. Groove cutting operation.

4. Keyway cutting operation 